\title{
Erratum to: Oxytocin enhances the appropriate use of human social cues by the domestic dog (Canis familiaris) in an object choice task
}

\author{
J. L. Oliva ${ }^{1}$ J.-L. Rault ${ }^{2}$ - B. Appleton ${ }^{3}$. \\ A. Lill ${ }^{1}$
}

Published online: 19 April 2015

(c) Springer-Verlag Berlin Heidelberg 2015

\section{Erratum to: Anim Cogn (2015) 18:767-775 \\ DOI 10.1007/s10071-015-0843-7}

Unfortunately, in the original publication the word 'receptor' under the sub-heading 'The effect of gender on the efficacy of oxytocin' has been incorrectly published as 'peptide'. The correct text should read as below.

Oestrogen is known to enhance the production of oxytocin and its receptor (Rissman 2008), and this may explain why the female dogs in this study did not perform as well as human female subjects in other tests of social cognition, as the majority ( $88 \%$ ) had been spayed, thereby reducing the volume of oestrogen their bodies would be producing.

The online version of the original article can be found under doi:10.1007/s10071-015-0843-7.

J. L. Oliva

jessica.oliva@monash.edu

1 School of Biological Sciences, Monash University, Melbourne, Australia

2 Animal Welfare Science Centre, University of Melbourne, Melbourne, Australia

3 Life and Environmental Sciences, Deakin University, Geelong, Australia 